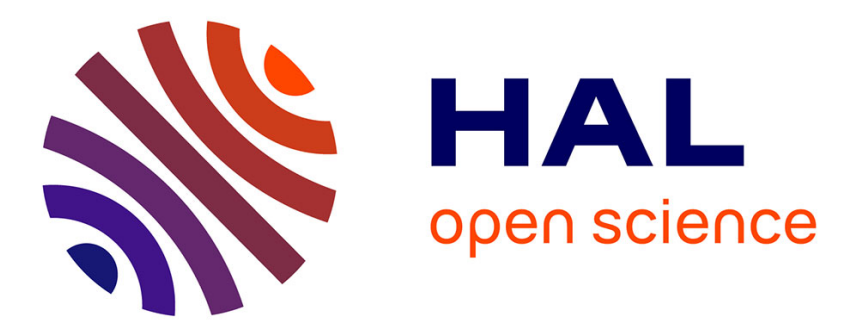

\title{
Buckling of stiffened curved panels under uniform axial compression
}

\author{
K. L. Tran, Cyril Douthe, Karam Sab, J. Dallot, L. Davaine
}

\section{To cite this version:}

K. L. Tran, Cyril Douthe, Karam Sab, J. Dallot, L. Davaine. Buckling of stiffened curved panels under uniform axial compression. Journal of Constructional Steel Research, 2014, 103, pp 140-147. 10.1016/j.jcsr.2014.07.004 . hal-01073382

\section{HAL Id: hal-01073382 \\ https://hal.science/hal-01073382}

Submitted on 9 Oct 2014

HAL is a multi-disciplinary open access archive for the deposit and dissemination of scientific research documents, whether they are published or not. The documents may come from teaching and research institutions in France or abroad, or from public or private research centers.
L'archive ouverte pluridisciplinaire HAL, est destinée au dépôt et à la diffusion de documents scientifiques de niveau recherche, publiés ou non, émanant des établissements d'enseignement et de recherche français ou étrangers, des laboratoires publics ou privés. 


\title{
Buckling of stiffened curved panels under uniform axial compression
}

\author{
K. L. Tran ${ }^{\mathrm{a}}$, C. Douthe ${ }^{\mathrm{b}, *}$, K. Sab ${ }^{\mathrm{c}}$, J. Dallot ${ }^{\mathrm{a}}$, L. Davaine ${ }^{\mathrm{d}}$ \\ ${ }^{a} S N C F$, Projet Système Ingénierie, Département des Ouvrages d'Art, 6, av. F. \\ Mitterrand, F-93574 La Plaine St Denis \\ ${ }^{b}$ Université Paris-Est, IFSTTAR, F-77447 Marne-la-Vallée Cedex 2 \\ ${ }^{c}$ Université Paris-Est, Laboratoire Navier (UMR 8205), ENPC, IFSTTAR, CNRS, \\ F-77455 Marne-la-vallée Cedex 2 \\ ${ }^{d}$ Ingérop, Expertises et Structure, 168/172, bd de Verdun, F-92408 Courbevoie
}

\begin{abstract}
In bridge construction, the use of stiffened plates for box-girder or steel beams is common day to day practice. The advantages of the stiffening from the economical and mechanical points of view are unanimously recognized. For curved steel panels, however, applications are more recent and the literature on their mechanical behaviour including the influence of stiffeners is therefore limited. Their design with commercial finite element software is significantly time-consuming, which reduces the number of parameters which can be investigated in an optimization procedure. The present paper is thus dedicated to the study of the behaviour of stiffened curved panels under uniform longitudinal compression. It addresses the linear buckling and the ultimate strength which are both influenced by the coupled effects of curvature and stiffening. It finally proposes a design methodology based on that for stiffened flat plates adopted by European Standards and a column-like behaviour.
\end{abstract}

\footnotetext{
* Corresponding author

Tel: +33181668136; e-mail: cyril.douthe@ifsttar.fr 
Keywords: Stiffened curved panels, Linear Buckling, Ultimate strength, GMNIA, Column-like behaviour

\section{Introduction}

Stiffened plates have been used for many years for the construction of bridges, for example in bottom flanges of box-girder bridges. The biggest advantage of the stiffeners is that they increase the bending stiffness of the panel with a minimum of additional material. Recently, improvement in the mechanical processes and numerical simulations allowed for the realisation of structures made of curved panels to gain in aerodynamic performance or to raise up new aesthetic feelings. The verification of such panels is however difficult due to a lack of specifications, especially in European Standards: EN 1993-1-5 [1] gives specifications for flat or slightly curved panels with the condition $R \geq R_{\text {lim }}=b^{2} / t_{p}$ - where $R, b$ and $t_{p}$ denote the curvature radius, the width and the thickness of the panel respectively - and EN 1993-1-6 [2] deals only with closed cylindrical shells. Yet curved panels in bridges have characteristics exactly between these two conditions: for example, in the case of the Confluences bridge in France (Fig. 1), current panels have a width of $4.8 \mathrm{~m}$, a thickness of $0.016 \mathrm{~m}$ and a radius of $80 \mathrm{~m}$ which is much smaller than the limit radius of EN 1993-1-5 which is equal to $1440 \mathrm{~m}$. EN 1993-1-6 is not applicable neither because these curved flanges are not full cylinders.

Actually, papers related to the buckling theory of curved panels are not so numerous due to the complexity of the studied problem and due to its late application in the bridge construction. First investigations were conducted by Batdorf \& Schildcrout [3] and Schildcrout \& Stein [4] in the years 40s. 
They dealt with a simple case with only one stiffener in the middle of the plate. The results showed on the one hand that the use of the stiffener is important to resist against buckling, and on the other hand that the effect of curvature also increases the critical buckling resistance. Becker [5] summarized the previous works on curved stiffened panels in its handbook on structural stability. Based on test results (provided by Gall [6], Lundquist [7] and Ramberg et al. [8]), Becker [5] showed that, when a flat panel is bent to a circular curve, its buckling strength increased. This means that the effective width of the panel acting with each stiffener increases with the curvature which then increases its column strength.

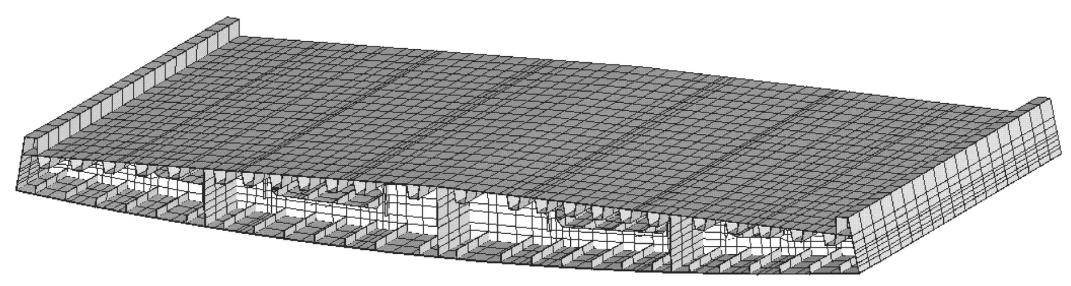

Figure 1: Bottom flange made of stiffened curved panels, Confluences Bridge, France.

Fig. 2 shows typical test results, realized by Ramberg et al. [8], where the ratio of curved to flat panel ultimate stresses, $\sigma_{a v}^{Z} / \sigma_{a v}^{\text {plate }}$, is plotted as a function of the curvature parameter $Z=b^{2} / R t_{p}$. It should be remarked here that Ramberg's specimen have stiffeners located on the external face of the panel. The gain in failure stress is visibly small, about $6 \%$ on the average and appears to decrease with increasing curvature. Anyway, Becker [5] insisted strongly that there is a serious need for additional test data on stiffened curved panels to really get insight of the influence of the numerous parameters. 


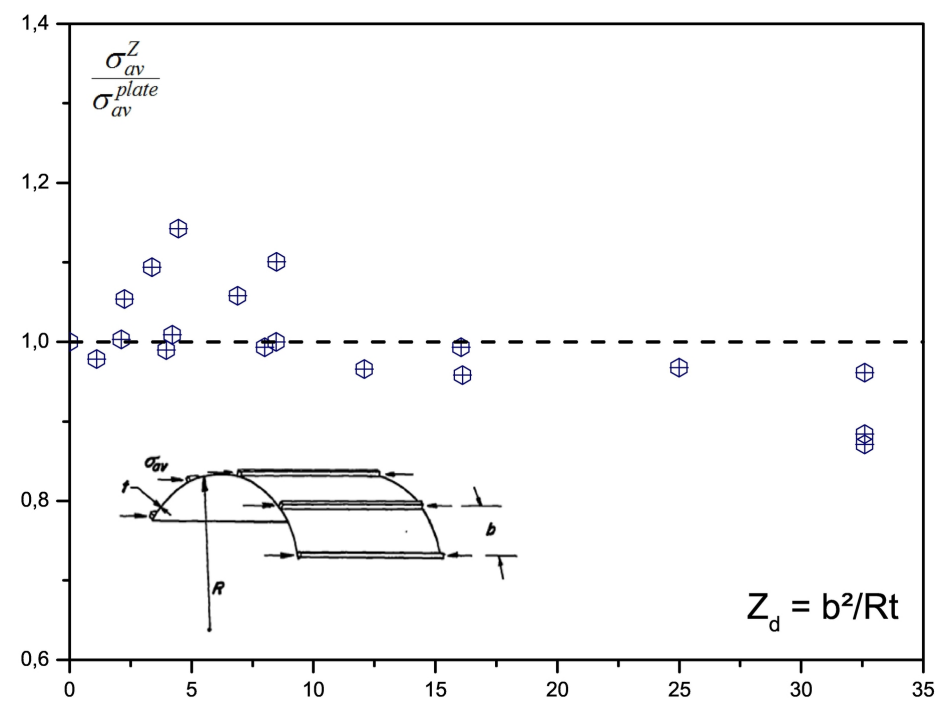

Figure 2: Effect of curvature on the axial compressive strength of stiffened panels [8].

Recently, the problem of stiffened curved plates showed a renewed interest by means of finite element modeling, for example in the works of Cho et al. [9], Khedmati \& Edalat [10] and Park et al. [11]. Their work consists in parametric studies where several parameters are varied to clarify their influence on the behavior of curved stiffened plates. Nevertheless they did not propose any criterion for the evaluation of the resistance of the panels. However the evaluation of the resistance of the panels is still an open question.

It is worth mentioning that there are theoretical and experimental researches on stiffened curved composite panels in the field of aeronautics, as for example during the European project POISICOSS (Zimmermann et al. [12] and [13]). Nevertheless, for composite panels, the stiffeners are linked to the bottom panels primarily by riveting. The collapse mode is thus essentially a separation of the different composite components or a dysfunction 
of the rivet. The design criterion being derived from these particular failure modes, these results can not directly be applied to panels encountered in civil engineering.

The stability of curved stiffened plates is thus a complex problem for which few approximates formulae for evaluating the ultimate strength exist today. Most studies have focused on panels used in aeronautics or marine construction which are very different from those encountered in bridges. A first approximate formula for preliminary design, based on design of experiments method, had been proposed by the authors in [14] and provided a first reliable tool for engineers. However, in its form this formula does not reflect the formalism of the Eurocode and it is not really suited for practical justification. One could thus be tempted to use the expressions of resistance for stiffened flat plates by neglecting the effects of curvature. Would this assumption be legitimate? in which cases? These are the two questions that this work will aim at answering. The objective of the present research is thus first to identify the buckling mechanism of stiffened curved panels, then to determine the range in which stiffened curved panels can be designed as stiffened flat panels by Eurocode and finally to propose a reliable design method (compatible with the Standard requirements) for panels with the highest curvature encountered in bridge engineering which can not be considered as stiffened flat panels.

To achieve this goal, the argument is structured as follow. The finite element model adopted in this study is first presented. Based on this model, the buckling behaviour and the ultimate strength are then investigated: the effect of curvature is studied together with other important parameters, such 
as the rigidity of stiffeners, their aspect ratio, their imperfection, etc. Based on the results of those simulations, a methodology for assessing the resistance of stiffened curved panels will be proposed.

\section{Finite element modelling}

The plates are modelled and analysed using the commercial finite element software Ansys version 11 [15]. The panels are supposed to be simply supported on all edges (the radial displacement $u_{r}$ is null in the cylinder coordinate system of Fig. 3) but not on the stiffeners (unfavourable condition).

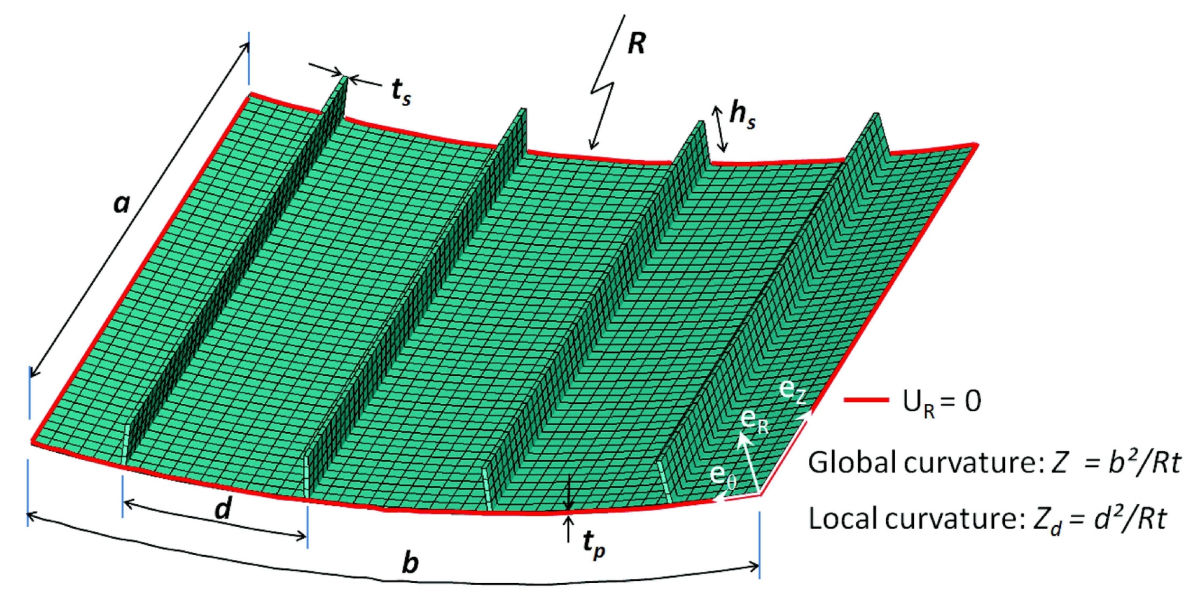

Figure 3: Characteristics of a stiffened curved panel simply supported on all edges.

Concerning loading conditions, the study is limited to a uniform compression in the longitudinal direction as it is the dominant loading in bottom flange panels. It is applied not only to the main panel, but also to the stiffeners due to their participation in the overall behaviour of the structure (Fig. 4). In fact, in a bridge, the compressive forces acting on the flange come through the diaphragms and webs that connect the upper and lower panels 
of the box girder. By construction, the stiffeners, in most cases, are continuous and attached by welding to diagrams: therefore they are also subjected to the compressive load.
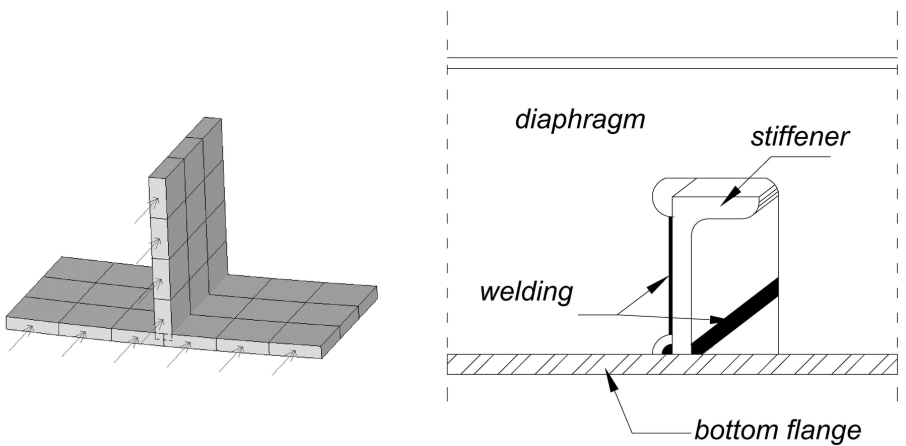

Figure 4: Loading condition and corresponding typical stiffener/diaphragm connection.

The curved panels are discretized with eight-nodes elements Shell 281 [15]. This type of element is well-suited for linear, large rotation and large strain nonlinear applications. Moreover, Shell 281 uses an advanced shell formulation that accurately incorporates initial curvature effects. This formulation offers improved accuracy in curved shell structure simulations and converges faster than plate elements Shell 181 (Braun [16]). A fine mesh with more than 30 elements per panel edges is used to reduce the discretisation error.

The panels are all made of steel which is assumed to be elastic perfectly plastic for the material non-linear analysis (MNA) and elastic-plastic with linear strain hardening as indicated in EN 1993-1-5 C.6 for the material non-linear second-order analyses with initial imperfections (GMNIA). The Young modulus $E$ and Poissons ration $\nu$ are taken equal to $210 G P a$ and 0.3 respectively. The steel grade is $\mathrm{S} 355$. 
The basic configuration of the studied panels is taken similar to that of the Confluences bridge. It has a fixed width $b$ of $4800 \mathrm{~mm}$ with a thickness $t_{p}$ of $12 \mathrm{~mm}$. The stiffeners are regularly spaced by a distance $d$ of $600 \mathrm{~mm}$ (there are thus 8 stiffeners in total). The curvature, the length of the panels and the geometry of the stiffeners ( $\mathrm{T}$ or simple flat) are the variable parameters whose influence on the buckling behaviour of stiffened curved panels is investigated in the following sections.

\section{Linear buckling analysis}

A series of linear buckling analyses is carried out to evaluate the buckling strength and to examine typical buckling modes of stiffened curved panels. The results are presented in Fig. 5 where the first buckling critical stress is plotted as a function of the global curvature parameter $Z=b^{2} / R t_{p}$.

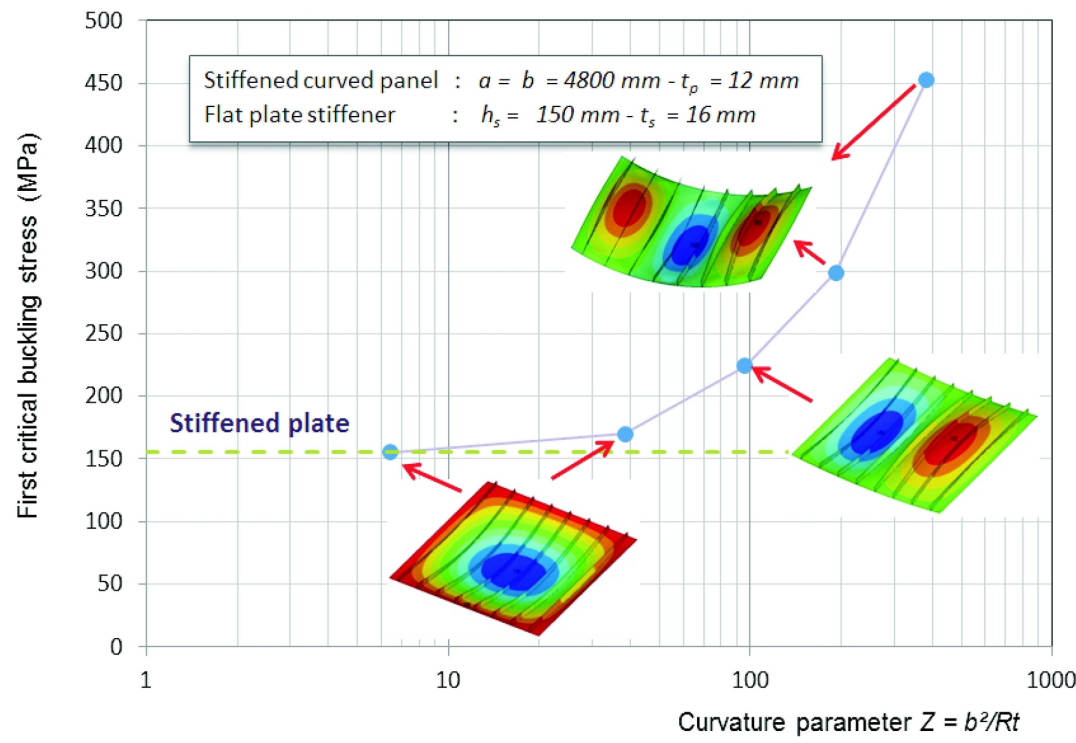

Figure 5: Values and shapes of the first buckling mode depending on the curvature. 
It is first noticed that the curvature increases the buckling stress, from the value of the stiffened flat plate (where $Z=0$ ) to a higher one for high curvatures. The asymptotic value of the critical stress can be assumed to follow a straight line, which, as believed by Soderquist [17], converges toward the buckling stress of a full longitudinal stiffened cylinder.

Fig. 5 shows that the curvature modifies also the buckling shape. The higher the curvature, the higher the number of half-waves $m$ in the circumferential direction (from $m=1$ for flat plates to $m=3$ for $Z=192$ ). This type of buckling is in accordance with the observations of Schildcrout \& Stein [4] and is very similar to the overall buckling mode of stiffened cylinders under axial compression.

Table 1: Coupled effect of aspect ratio and curvature on the relative buckling stress.

\begin{tabular}{ccccc}
$Z \backslash \alpha$ & 1.0 & 1.5 & 2.0 & 3.0 \\
\hline 0 & 1.00 & 1.00 & 1.00 & 1.00 \\
6.4 & 1.11 & 1.12 & 1.13 & 1.11 \\
38.4 & 1.21 & 1.36 & 1.47 & 1.50 \\
96 & 1.60 & 2.16 & 3.17 & 3.75 \\
192 & 2.14 & 3.30 & 4.52 & 6.53 \\
384 & 3.11 & 5.69 & 8.80 & 10.99 \\
\hline
\end{tabular}

The influence of the curvature is however not independent from other parameters. Indeed, table 1 presents the ratio of curved to flat panels buckling stress $\sigma_{c r}^{Z} / \sigma_{c r}^{\infty}$ in function of two parameters: the curvature $Z$ and the aspect ratio $\alpha=a / b$. It is found that there is a significant interaction between these two parameters: the influence of curvature is greater if the plate length 
increases. For example, for a square panel $(\alpha=1)$, the buckling stress for curved panels $(Z=384)$ is three times that of a flat plate with the same dimensions $(Z=0)$. This factor is equal to 11 if the aspect ratio $\alpha$ is set equal to 3 .

It is thus concluded that the curvature increases the elastic buckling resistance of curved stiffened plates. The higher the curvature, the greater the effect. The curvature also changes the shape of buckling: the number of half-waves in the circumferential direction increases with the curvature. Moreover, there is evidence of a strong positive interaction of the aspect ratio and the curvature.

\section{Ultimate strength}

The ultimate strength of the panels is evaluated numerically using nonlinear analysis including geometrical and material imperfections (GMNIA). These simulations are conducted using the arc-length method which allow to follow the load-displacement curve when entering into the post-buckling regime until the ultimate strength is reached. For such an iterative method, it is necessary to select suitable criteria ( $L_{2}$-norm of force and moment) for the convergence and the termination of the calculus. The criterion is thus reached when the actual residual is lower than $0.5 \%$ of the initial residual which is appropriate for most engineering applications. The effect of curvature is investigated via three important parameters (initial imperfection, aspect ratio and the relative flexural stiffness of the stiffener), issued from the parametric study on stiffened panels by Grondin et al. [18]; Ghavami et al. [19] and on parabolic curved panels by Khedmati \& Edala [10]. 


\subsection{Influence of imperfections}

As in many stability problems, the modelling of initial imperfections is important. Typical imperfection of cylindrical panel studied by Soderquist [17] are shown in Fig. 6. It is noticed that the differences of the local curvature radii are significant, the maxima difference $\left(\triangle R=\frac{R_{\max }-R_{\min }}{R_{\text {nominal }}}\right)$ reaching $20.5 \%$. It is also noticed that imperfections concentrate in the vicinity of stiffeners. It appears hence necessary to take these imperfections into account for calculating the ultimate strength of the panel. However, the distribution of imperfections depends on so many parameters, that practically the actual pattern can only be the result of a standardization process.

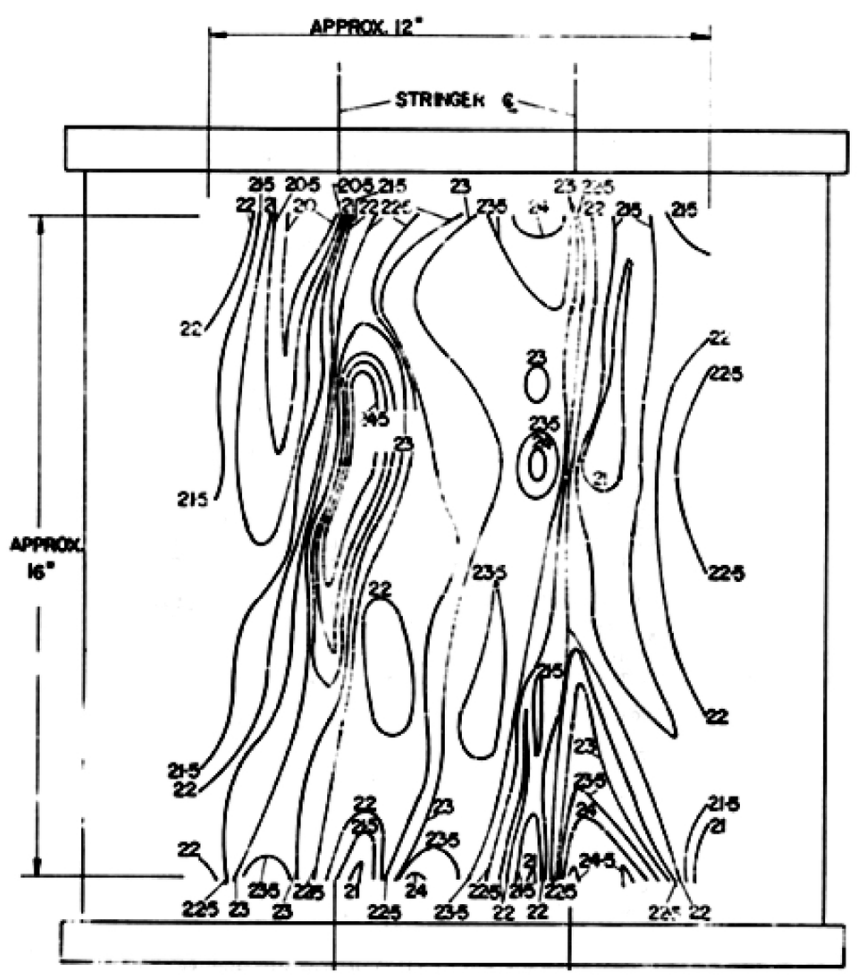

Figure 6: Contour mapping of the local curvature radii measured by Soderquist [17]. 
Taking into account the fact that the fabrication process of curved panels is similar to that of plates, it seems reasonable to use the equivalent initial imperfection given by EN 1993-1-5. To validate this assumption, a sensitivity analysis is conducted based on the suggestions of EN 1993-1-5 table C.2. Several models of imperfection are taken based on:

- Model $n^{\circ} 1$ : Global imperfection of stiffeners (Fig. 7), issued from the shape of the global buckling mode of the panel.

- Model $n^{\circ}$ 2: Local imperfection of sub panel (Fig. 8). This model is based on the critical buckling mode of a model where the transversal displacements (out-of-plane) of stiffeners are blocked.

- Model $n^{\circ}$ 3: Local imperfection by torsion of stiffeners (Fig. 9), defined on the basis of the elastic deformation of a model where the stiffeners are clamped at the junction with the panel and are subjected to a horizontal force in the middle length of stiffeners.

- Model $n^{\circ} 4$ : Combination of imperfections. The combination is done in a probabilistic manner where one leading imperfection is taken with full magnitude and the others may be taken as $70 \%$ of their full value. Here, three combinations have been studied:

$$
\begin{aligned}
& \text { - Model } n^{\circ} 4 a:(4 a)=1.0 *\left(n^{\circ} 1\right)+0.7 *\left(n^{\circ} 2\right)+0.7 *\left(n^{\circ} 3\right) \\
& \text { - Model } n^{\circ} 4 b:(4 b)=0.7 *\left(n^{\circ} 1\right)+1.0 *\left(n^{\circ} 2\right)+0.7 *\left(n^{\circ} 3\right) \\
& \text { - Model } n^{\circ} 4 c:(4 c)=0.7 *\left(n^{\circ} 1\right)+0.7 *\left(n^{\circ} 2\right)+1.0 *\left(n^{\circ} 3\right)
\end{aligned}
$$

The imperfection modes mentioned above are easily introduced into the finite element model using a command which updates the geometry of the 


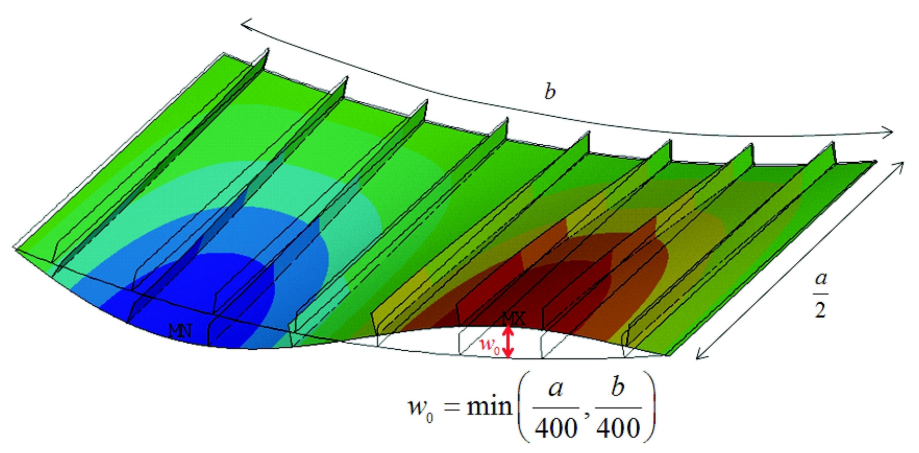

Figure 7: Global imperfection at mid-section of the panel.

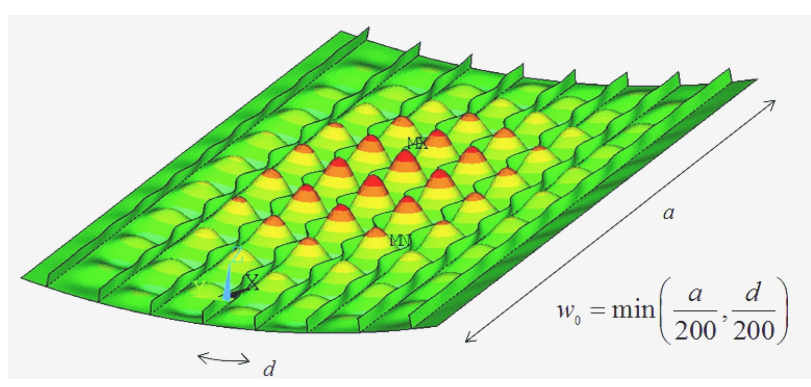

Figure 8: Local imperfection of the sub-panels.

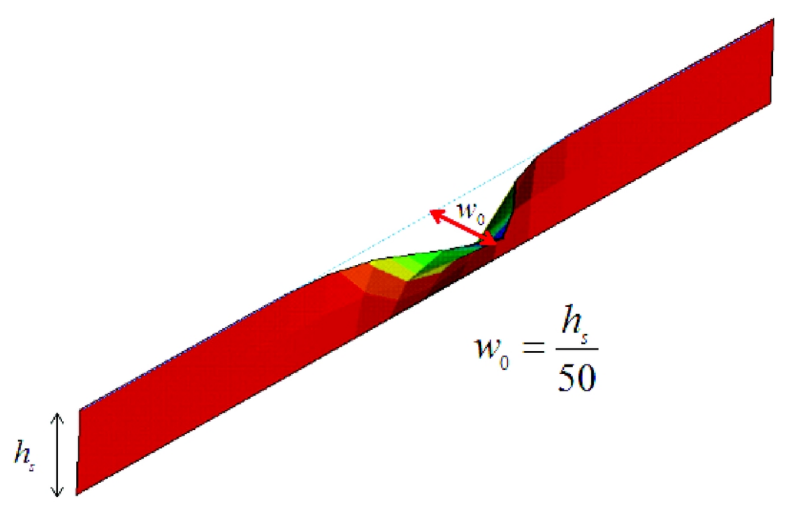

Figure 9: Local torsional imperfection of a stiffener. 
finite element model according to the displacement results of the previous analysis and creates a revised geometry. This command works on all nodes (default) or on a selected set of nodes. If this command is issued repeatedly, it creates a revised geometry of the finite element model in a cumulative fashion, i.e. it adds displacement results on the previously generated deformed geometry.

Table 2: Influence of various shape imperfections on the ultimate strength.

\begin{tabular}{ccccccc}
\hline$\alpha$ & $n^{\circ} 1$ & $n^{\circ} 2$ & $n^{\circ} 3$ & $n^{\circ} 4 a$ & $n^{\circ} 4 b$ & $n^{\circ} 4 c$ \\
\hline 0.75 & 0.717 & 0.801 & 0.965 & 0.720 & 0.746 & 0.744 \\
1.00 & 0.666 & 0.732 & 1.000 & 0.662 & 0.674 & 0.679 \\
2.00 & 0.515 & 0.761 & 0.953 & 0.511 & 0.510 & 0.508 \\
\hline
\end{tabular}

The results of a study conducted for a panel with a $10 \mathrm{~m}$ radius are presented in table 2 for three values of the aspect ratio $\alpha$ (essentially in the middle range of length where the imperfections have the most influence). The ultimate strengths of panels are identified for each aspect ratio as the minimum value in table 2 . Their analyses bring to the following remarks:

- The ultimate load varies with the form of imperfection. The maximum percentage difference between the largest and the smallest value can reach up to $47 \%$ (for $\alpha=2$ ).

- The model of imperfection based on the local imperfection of stiffener (model $n^{\circ} 3$ ) has a very limited influence on the ultimate load.

- In the studied example, model $n^{\circ} 1$ is nearly the most critical one for 
all cases (with a maximum deviation from the smallest value of only $1.4 \%$ when $\alpha=2$ ). The global imperfection is thus the dominant imperfection. This strong influence can be understood considering that this imperfection mode introduces compression in the stiffener which is a potentially unstable configuration (Fig. 10).

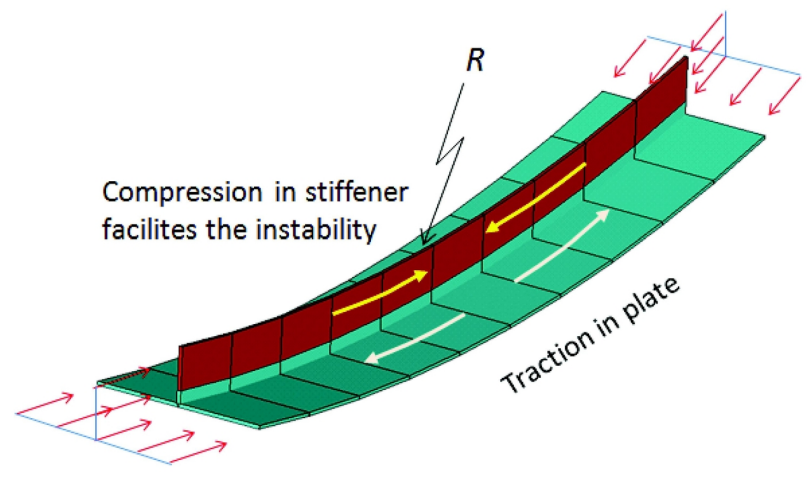

Figure 10: Influence of global imperfections on the stresses in the stiffener.

In conclusion, it has been shown that the influence of initial imperfection on the value of the ultimate strength can be relatively important. For complex structures that consist of several secondary structures such as stiffened panels, it is difficult to find the most critical mode without a comprehensive analysis of all possible modes of imperfections. However, for open crosssection of stiffeners, it seems reasonable to assume that the global buckling of stiffener's model (alone or together with secondary local imperfection of sub-panels) is dominant. This mode of imperfection will thus be used in the next sections. 


\subsection{Influence of the aspect ratio}

In the case of stiffened flat plates, the aspect ratio $\alpha=a / b$ is an important parameter. Indeed, stiffened plates generally have a column-like behaviour for small values of $\alpha$ and a plate-like behaviour for large values of $\alpha$. Fig. 11 shows the ultimate loads as function of the aspect ratio $\alpha$ for three values of the radius of curvature: (1) $R=1920 \mathrm{~m}$ for which the global curvature parameter $Z=b^{2} / R t_{p}=1$; (2) $R=30 \mathrm{~m}$ for which the local curvature parameter $Z_{d}=d^{2} / R t_{p}=1$; and (3) $R=10 \mathrm{~m}$ for a configuration of very curved panels (rarely used in bridge construction). The first two cases ( $R=1920 \mathrm{~m}$ and $R=30 \mathrm{~m}$ ) are selected to examine the limits of EN 19931-5 whose ultimate strength for a similar stiffened plate is also presented (see continuous curve in Fig. 11).

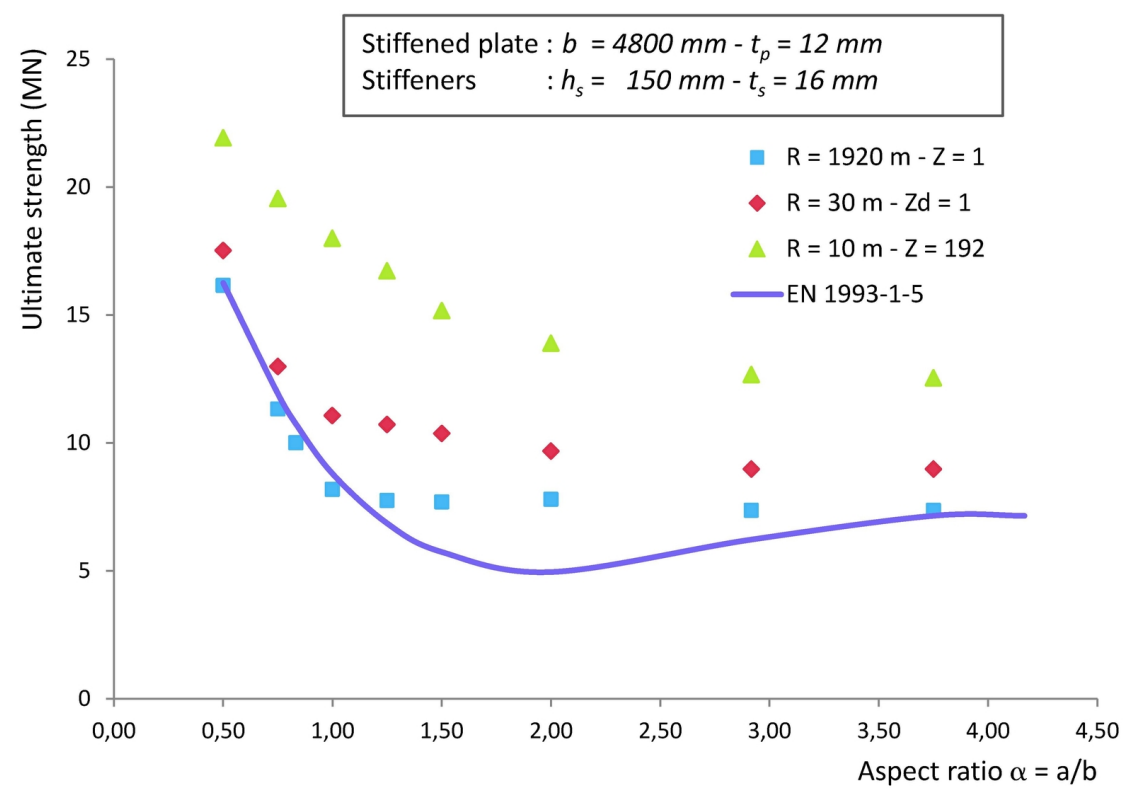

Figure 11: Effect of curvature on the ultimate strength. 
These results, which are raw values from the finite element simulations without any consideration of safety factor, bring the following remarks:

- First of all, the curvature increases the ultimate strength of panels, especially in the range of intermediate panels $(1<\alpha<2)$. This confirms the observations in the literature mentioned above [5].

- The ultimate strength of the stiffened curved panels is significantly influenced by the aspect ratio $\alpha$ as in the case of stiffened flat panel: it decreases when $\alpha$ increases.

- For $Z=b^{2} / R t_{p}=1$, the numerical results can be estimated by European standard (EN 1993-1-5) prediction's curve. It is thus concluded that the domain of validity of EN 1993-1-5 defined by the condition $R>b^{2} / t_{p}$ is satisfactory and secure. Also, the risk of under-estimation for the intermediate panels can be corrected by using De Ville de Goyet et al. [20] proposition, which is, in our opinion, the best interpolation behaviour of stiffened plates (see the discussion in [21]).

- For $Z_{d}=d^{2} / R t_{p}=1$, the numerical results are all above of the European standard curve (about $20 \%$ in average with a maximum of $38 \%$ ). This observation is interesting and motivates a proposition for expanding the scope of EN 1993-1-5, in which the value of the parameter b in the condition $b^{2} / t_{p}<R$ is replaced by the value of $\mathrm{d}$ in the case of stiffened panels. With this modification, most stiffened curved plates in the field of structures can be covered, on the safety side, by recommendation for stiffened flat plate (by neglecting the increasing effect of curvature). 
- The increase of the ultimate load is higher if the curvature is significant. For example, if $R=10 \mathrm{~m}$, the ultimate load is double compared to that of a flat plates (120\% higher more precisely) for intermediate panel and about $70 \%$ for long panels. Not considering here its effect becomes thus very unfavourable.

\subsection{Influence of the stiffeners rigidity}

According to the work of Bedair [22], the rigidity of the stiffeners is an important parameter influencing the behaviour of stiffened plates. In this section, the behaviour of panels with simple flat stiffeners is thus compared to that of panels with T-shape stiffeners. Their cross section is chosen identical $\left(A=24 \mathrm{~cm}^{2}\right)$ but their second moment of area is different $\left(I_{T-\text { shape }}=\right.$ $\left.0.30 \cdot 10^{8} \mathrm{~mm}^{4}>I_{\text {flat plate }}=0.18 \cdot 10^{8} \mathrm{~mm}^{4}\right)$. The values of the ultimate strength for flat plates are presented in Fig. 12a which shows that the use of T-shape stiffeners is more efficient than that of simple flat stiffeners with a gain of about $40 \%$ for $\alpha=1$. Indeed, the flanges of T-shape stiffeners are located far away from the panel neutral axis, they provide thus more bending inertia than flat plate stiffeners (about 6 times).

However, this gain becomes less significant when the curvature increases: it is of only $8 \%$ when $R=10 \mathrm{~m}$ (see Fig. 12). The reason is that the position of the center of gravity of the section relatively to the panel changes with the curvature: from $26.8 \mathrm{~mm}$ for flat plate $(R=\infty)$ to $121.9 \mathrm{~mm}$ for $R=10 \mathrm{~m}$. The curvature raises the center of gravity toward the center of curvature, which is closer to the stiffener flanges (see Fig. 13). This leads to a decrease of the second moment of area induced by the stiffeners, therefore the efficiency of the $\mathrm{T}$ stiffeners is reduced. 

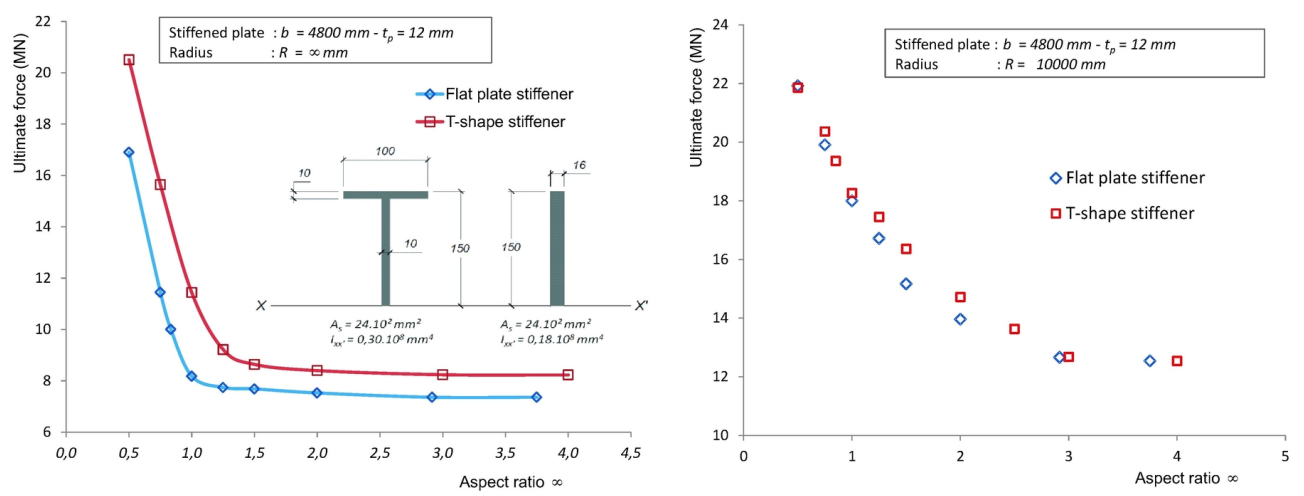

Figure 12: Influence of the rigidity of the stiffener: $R=\infty$ (left), $R=10 m$ (right).

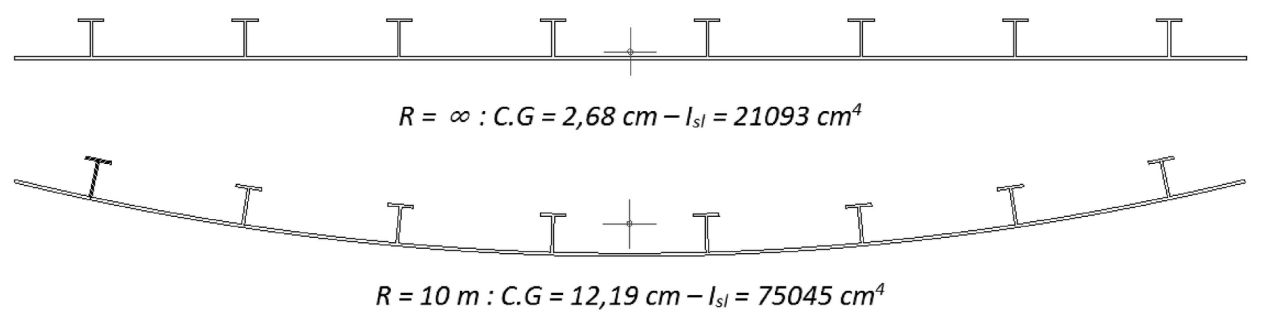

Figure 13: Influence of the curvature on the centre of gravity height and the inertia $I_{s l}$.

Table 3 shows some typical values of moments of inertia (calculated on the total cross section). As the second moment of area is linked directly to the stiffness of the panel, these values are very interesting and can thus explain most previous remarks. Indeed for a flat plate, using stiffeners is extremely useful because it increases the structural strength without making the structure heavier. An increase of 190 times the inertia of the panel is obtained by simply adding single flat stiffeners. The use of T-shape stiffeners instead of flat ones induces then an additional increase of $61 \%$, which explains the results in Fig. 12b. 
Table 3: Influence of the stiffeners shape on the inertia $\left[\mathrm{cm}^{4}\right]$.

\begin{tabular}{cccc}
\hline & Without stiffener. & Simple plate & T-shape \\
\hline$R=\infty$ & 69 & 13116 & 21093 \\
$R=10 m$ & 42172 & 67394 & 75045 \\
\hline
\end{tabular}

For curved stiffened panels, the curvature itself increases significantly the stiffness of the panel: a panel with a radius of $10 \mathrm{~m}$ is more than 5 times than a flat plate stiffened by simple flat stiffeners. This observation may explain why the increase in the ultimate load of stiffened curved plates is less significant (Fig. 12). Moreover, for curved panels, T-shape stiffeners provide only $11.5 \%$ more inertia than flat plate stiffeners, so that using T-stiffener is not as attractive as in the case of flat plates.

So, based on the parametric studies conducted above and on the literature review, it is concluded that the curvature increases the ultimate strength of panels by raising their second moment of area. This effect is marginal in panels with small curvature where stiffened curved panels can be treated as equivalent stiffened flat plates. However, this effect becomes significant when the curvature increases. Therefore, in order to optimize the design of such panels, the effect of the curvature must be properly taken into account. To this end, an approximate model is developed in next section.

\section{Design methodology}

At this stage, our previous analyses using finite element modelling confirm that the behaviour of stiffened curved panels is a complex problem, 
especially due to the interaction of the curvature, the relative rigidity of stiffeners and the imperfections. The development of a simple (i.e. suited for hand-calculation) and reliable (i.e. in good agreement with numerical results and with Eurocode formalism) method which would give the ultimate resistance of such panels with a reasonable precision becomes thus desirable for practical applications by engineers.

\subsection{Choice of the methodology}

As the curvature of panels used for bridge construction is not significant, the solution is naturally derived from the model of resistance for stiffened flat plates. According to EN 1993-1-5, the collapse load can be evaluated by interpolation of two distinct asymptotic behaviours: a column-like behaviour without any post-buckling resistance and plate-like behaviour with post-buckling resistance.

In a previous work [23], the authors had shown that, for unstiffened curved panels under uniform axial compression, the limit proposed by EN 1993-15 for the curvature $Z\left(Z=b^{2} / R t_{p} \leq 1\right)$ was satisfactory. For stiffened curved panels, numerical simulations detailed in section 4.2 have shown that this limit can actually be extended to the local curvature of the panels $Z_{d}$ defined by $d^{2} / R t_{p}$ where $d$ denotes the distance between stiffeners. Indeed within this range, neglecting the beneficial effect of curvature leads to an underestimation of the ultimate strength which remains smaller than $20 \%$, as can be seen in Fig. 11.

For higher local curvatures (i.e. for $Z_{d} \geq 1$ ), the positive effect of curvature can no longer be neglected. So, depending on the design stages, two different methodologies can be used. In a preliminary design stage, the for- 
mula developed in [14] provides a reliable and straightforward way to evaluate the ultimate strength. In a final design stage, engineers will prefer to use a methodology closer to the Standards formalism. Therefore, considering that:

i) the range of the aspect ratios in civil engineering applications is reduced (for example, in the Confluence bridge in Fig. 1, the 300 curved panels of the girder have an aspect ratio $\alpha=a / b$ smaller than 1.25 ,

ii) for reduced aspect ratios stiffened curved panels failure is governed by a column-like buckling,

a criterion based on column-like behaviour will be developed in the coming section.

Such a criterion has already been adopted in several standards for stiffened plates [24], for simplicity reason and also because it always provides an estimation of the ultimate strength on the safety side. Indeed, the basis of the column-like approach for flat panels is to treat a stiffened panel as a series of unconnected compression "struts" where a "strut" consists of a longitudinal stiffener acting together with the associated width of plate between stiffeners. The two unloaded edges of a "strut" are assumed to be free. No membrane effects, which are characteristic of panels, can take place and hence there is no post-buckling reserve. As a consequence, this approach provides a lower bound of the ultimate strength.

\subsection{Ultimate strength by column-like behaviour}

The proposed methodology thus consists in considering that the ultimate strength of curved stiffened panels under uniform axial compression can be evaluated from a standard column buckling problem by EN 1993-1-1 [25]. 
Therefore, the first step consists in the determination of elastic buckling stress $\sigma_{c r}$, also known as Euler stress:

$$
\sigma_{c r}=\frac{\pi^{2} E I_{s l}}{A_{s l} a^{2}}
$$

As for stiffened flat panels, $A_{s l}$ and $I_{s l}$ are the area and the second moment of inertia for longitudinal bending of the "strut" model. However, for stiffened curved panels, it is not relevant to disconnect the stiffeners and to analyse every column separately. Indeed, as seen in section 4.3, the curvature itself has a very strong influence on the bending inertia of the stiffened panel. As presented in Fig. 13, the inertia of the whole stiffened plate is equal to the sum of those of 8 strut models $\left(I_{s l}^{R=\infty}=21093 \mathrm{~cm}^{4}=8 \cdot I_{s l, s t r u t}=8 \cdot 2636 \mathrm{~cm}^{4}\right)$ whereas it is not the case for the curved stiffened panels $R=10 \mathrm{~m}\left(I_{s l}^{R=10 \mathrm{~m}}=\right.$ $75045 \mathrm{~cm}^{4}>8 \cdot I_{\text {sl,strut }}=8 \cdot 2550 \mathrm{~cm}^{4}=20400 \mathrm{~cm}^{4}$ ). For curved panels, the appropriate strut model is thus the whole panel and the area and inertia must be evaluated on the whole model.

Then, in the second step, this elastic buckling stress is used to determine the reduced slenderness $\bar{\lambda}$ taking into account class 4 portions of the section through the introduction of the ratio between the effective area $A_{c, \text { eff }}$ (evaluated by the standard Eurocode procedure) and the gross cross-sectional area $A_{s l}$.

$$
\bar{\lambda}=\sqrt{\frac{A_{c, e f f}}{A_{s l}} \frac{f_{y}}{\sigma_{c r}}}
$$

Afterwards, the imperfection parameter $\alpha_{e}$ is evaluated from the gyration radius $i=\sqrt{I_{s l} / A_{s l}}$ of the whole panel and from the characteristic eccentricity of the loading $e$ which is defined by $\max \left(G_{1}-G ; G\right)$ where $G$ is the distance between the centre of gravity of the stiffened panel and the middle 
plane of the panel and $G_{1}$ is the distance between the centre of gravity of the stiffeners only and the middle plane of the panel .

$$
\alpha_{e}=\alpha+\frac{0.09}{i / e}
$$

In most cases, $\alpha$ is equal to 0.49 as the panels are generally stiffened by open sections and follow the buckling curve c) of EN 1993-1-1.

Then the reduction factor $\chi_{c}$ is obtained from the parameter $\phi$ by:

$$
\chi_{c}=\frac{1}{\phi+\sqrt{\phi^{2}-\bar{\lambda}^{2}}} \quad \text { with } \phi=0.5\left[1+\alpha_{e}(\bar{\lambda}-0.2)+\bar{\lambda}^{2}\right]
$$

And finally the ultimate strength of the curved panel is deduced:

$$
N_{R d}=\chi_{c} \cdot A_{c, e f f} \cdot f_{y}
$$

Fig. 14 shows the comparison of the proposed methodology and numerical simulations for panels with a curvature radius of $10 \mathrm{~m}$, a thickness of $12 \mathrm{~mm}$ and a width of $4.8 \mathrm{~m}$ stiffened by 8 simple flats separated by $600 \mathrm{~mm}$ with a height $h_{s}$ of $150 \mathrm{~mm}$ and a thickness $t_{s}$ of $16 \mathrm{~mm}$ (which corresponds to $Z=b^{2} / R t_{p}=192 \geq 1$ and to $Z_{d}=d^{2} / R t_{p}=3 \geq 1$ ). It can be seen that the agreement is very good in the studied range of aspect ratio (and becomes less accurate for higher values of $\alpha$ ). It appears also that the estimation of the ultimate strength is much better than the one obtained with the Eurocode for stiffened flat plates. It is thus concluded that the column-like approach provides a reliable and safe method for the estimation of the strength of curved stiffened panels. 


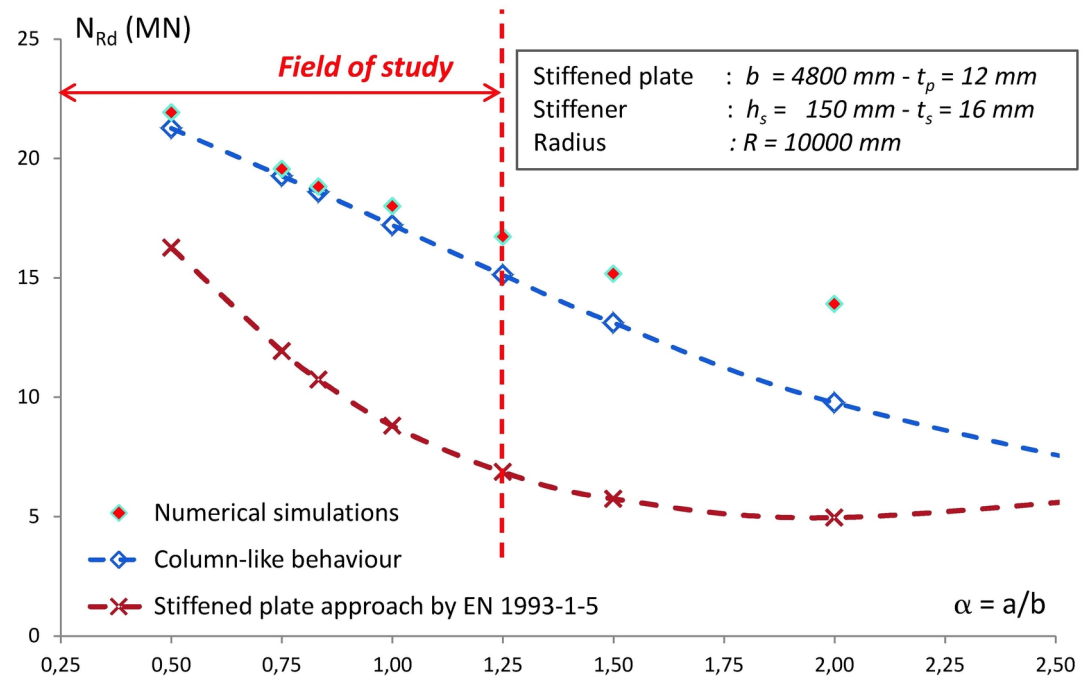

Figure 14: Ultimate strength of curved stiffened panels by a column-like approach.

\section{Conclusion}

The buckling behaviour of stiffened curved panel subjected to a uniform axial compression has been investigated in the present paper, focusing on the practical range of bridge engineering applications. In comparison with stiffened flat plates which have been studied for a long time, the most significant effects of curvature can be summarised as follow.

- For elastic buckling, the curvature modifies the global shape of the buckling mode. The higher the curvature, the higher the number of half-waves in circumferential direction. The buckling mode for a very high curvature is hence very close to that of longitudinal stiffened cylinder.

- The curvature increases the second moment of inertia leading to a higher elastic buckling stress of curved panels and to a higher ultimate 
strength.

- The influence of the shape of the stiffeners is limited due to the fact that the curvature already rises the height of the centre of gravity. The main role of the stiffeners is thus to avoid local buckling.

Concerning the design methodology of such panels, two propositions have been made in complement to the preliminary design formula which had been proposed in [14].

- The limitation on the curvature given by EN 1993-1-5 can be reasonably considered as a limitation on the local curvature defined by $Z_{d}=d^{2} / R t_{p}$ rather than on the total curvature, so that most stiffened curved panels with a usual density of stiffeners are covered by the verification of stiffened flat plates. The evaluation of ultimate strength obtained hence remains on the safety side (as the positive effect of curvature are not taken into account) but the underestimation is limited (lower than $20 \%$ ).

- For panels with high curvature which are not covered by the Eurocode verification (panels for which $Z_{d} \geq 1$ ), a simple methodology based on a column-like approach of the whole panel can been used and provide a very reliable and safe estimation of the ultimate strength. 


\section{Nomenclature}

$\alpha \quad$ aspect ratio $(\alpha=a / b)$

$\chi_{c} \quad$ column buckling reduction factor

$\bar{\lambda} \quad$ relative slenderness parameter

$A_{s l}$ gross cross sectional area of the whole panel

$b \quad$ width of a stiffened panel

$d \quad$ distance between stiffeners

$f_{y} \quad$ yield strength

$I_{s l} \quad$ second moment of the area of whole panel

$N_{R d}$ design resistance force

$t_{s} \quad$ stiffener thickness

$Z, Z_{d}$ global and local curvature parameter $\left(Z=b^{2} / R t_{p}, Z_{d}=d^{2} / R t_{p}\right)$

$\sigma_{c r} \quad$ elastic buckling stress for the equivalent strut model

a length of a stiffened panel

$A_{c, \text { eff }}$ effective cross sectional area

E elastic modulus

$h_{s} \quad$ height of stiffeners

$t_{p} \quad$ panel thickness 


\section{List of Figures}

1 Bottom flange made of stiffened curved panels, Confluences Bridge, France. . . . . . . . . . . . . . . . . 3

2 Effect of curvature on the axial compressive strength of stiffened panels [8]. . . . . . . . . . . . . . . . . . . . . . . . 4

3 Characteristics of a stiffened curved panel simply supported on all edges. . . . . . . . . . . . . . . . . . . 6

4 Loading condition and corresponding typical stiffener/diaphragm connection. ................... 7

5 Values and shapes of the first buckling mode depending on the curvature. ...................... . . . 8

6 Contour mapping of the local curvature radii measured by Soderquist [17]. . . . . . . . . . . . . . . . . . . 11

$7 \quad$ Global imperfection at mid-section of the panel. . . . . . . . . 13

8 Local imperfection of the sub-panels. . . . . . . . . . . . 13

9 Local torsional imperfection of a stiffener. . . . . . . . . . . 13

10 Influence of global imperfections on the stresses in the stiffener. 15

11 Effect of curvature on the ultimate strength. . . . . . . . . 16

12 Influence of the rigidity of the stiffener: $R=\infty$ (left), $R=$ $10 m$ (right). . . . . . . . . . . . . . . . . . 19

13 Influence of the curvature on the centre of gravity height and the inertia $I_{s l} \ldots \ldots \ldots \ldots \ldots \ldots$

14 Ultimate strength of curved stiffened panels by a column-like approach. .................. 25 


\section{List of Tables}

1 Coupled effect of aspect ratio and curvature on the relative buckling stress. . . . . . . . . . . . . . . . . . 9

2 Influence of various shape imperfections on the ultimate strength. 14

3 Influence of the stiffeners shape on the inertia $\left[\mathrm{cm}^{4}\right] \ldots$. . . . 20 


\section{References}

[1] EN 1993-1-5 : Design of steel structures, Part 1-5 : Plated structural elements. CEN, Brussels; 2007.

[2] EN 1993-1-6 : Design of steel structures, Part 1-6 : Strength and stability of shell structures. CEN, Brussels; 2007.

[3] Batdorf S, Schildcrout M. Critical axial-compressive stress of a curved rectangular panel with a central chordwise stiffener. Tech. Rep.; 1948.

[4] Schildcrout M, Stein M. Critical axial-compressive stress of a curved rectangular panel with a central longitudinal stiffener. Tech. Rep.; NACA Technical Note 1879; 1949.

[5] Becker H. Handbook of structural stability. Part VI: Strength of stiffened curved plates ans shells. Tech. Rep.; New York University, Washington; 1958.

[6] Gall H. Compressive strength of stiffened sheets of aluminum alloy. Ph.D. thesis; Massachusetts Institute of Technology; 1930.

[7] Lundquist E. Comparison of three methods for calculating the compressive strength of flat and slightly curved sheet and stiffener combinations. Tech. Rep.; National Advisory Committee for Aeronautics, TC $455 ; 1933$.

[8] Ramberg W, Levy S, Fienup K. Effect of curvature on strength of axially loaded sheet-stringer panels. Tech. Rep.; NACA-Technical note $944 ; 1944$. 
[9] Cho S, Park H, Kim H, Seo J. Experimental and numerical investigations on the ultimate strength of curved stiffened plates. In: Proceeding 10th International Symposium on Practical Design of Ships and Other Floating Structures. 2007,.

[10] Khedmati M, Edalat P. A numerical investigation into the effects of parabolic curvature on the buckling strength and behaviour of stiffened plates under in-plane compression. Latin American Journal of Solids and Structures 2010;7(3).

[11] Park J, Iijima K, Yao T. Estimation of buckling and collapse behaviours of stiffened curved plates under compressive load. International Society of Offshore and Polar Engineers, USA; 2008,.

[12] Zimmermann R, Klein H, Kling A. Buckling and postbuckling of stringer stiffened fibre composite curved panels: tests and computations. Composite Structures 2006;73(2):150-61.

[13] Zimmermann R, Rolfes R. Posicoss-improved postbuckling simulation for design of fibre composite stiffened fuselage structures. Composite Structures 2006;73(2):171-4.

[14] Tran K, Douthe C, Sab K, Davaine L, Dallot J. A preliminary design formula for the strength of stiffened curved panels by design of experiment method. Thin-Walled Structures 2014;79:129-37.

[15] ANSYS . User's theory manual v11. 2007.

[16] Braun B. Stability of steel plates under combined loading. Ph.D. thesis; University of Stuttgart; 2010. 
[17] Soderquist A. Experimental investigation of stability and post buckling behaviour of stiffened curved plates. Institute of Aerophysics, University of Toronto; 1960.

[18] Grondin G, Elwi A, Cheng J. Buckling of stiffened steel plates - A parametric study. Journal of Constructional Steel Research 1999;50(2):15175 .

[19] Ghavami K, Khedmati M. Numerical and experimental investigation on the compression behaviour of stiffened plates. Journal of Constructional Steel Research 2006;62(11):1087-100.

[20] De Ville De Goyet V, Maquoi R, Bachy F, André I. Ultimate load of stiffened compressed plates: Effects of some parameters and discussion concerning the ec3 rules. In: Proceedings of the Third European Conference on Steel Structures; vol. 1. 2002, p. 591-600.

[21] TRAN K. Etude de la stabilité et de la résistance des tôles courbes cylindriques. applications aux ouvrages d'art. Ph.D. thesis; Université Marne-La-Vallée; 2012.

[22] Bedair O. Analysis and limit state design of stiffened plates and shells: A world view. Applied Mechanics Reviews 2009;62(2):020801-16.

[23] Tran K, Davaine L, Douthe C, Sab K. Stability of curved panels under uniform axial compression. Journal of constructional steel research $2012 ; 69(1): 30-8$. 
[24] Bonello M, Chryssanthopoulos M, Dowling P. Ultimate strength design of stiffened plates under axial compression and bending. Marine structures 1993;6(5-6):533-52.

[25] EN 1993-1-1 : Design of steel structures, Part 1-1 : General rules and rules for buildings. CEN, Brussels; 2005. 